\title{
ANÁLISE DA COMPETITIVIDADE DAS EXPORTAÇÕES DO COMPLEXO SOJA BRASILEIRO DE 1995 A 2006: UMA ABORDAGEM DE MARKET-SHARE*
}

\author{
Daniel Arruda Coronel ${ }^{* *}$
}

\author{
João Armando Dessimon Machado ${ }^{* * *}$
}

\section{Fátima Marília Andrade de Carvalho ${ }^{* * *}$}

\begin{abstract}
RESUMO Este artigo objetivou identificar o comportamento das exportações do complexo soja brasileiro de 1995 a 2006, utilizando o modelo de comércio internacional Constant-Market-Share para os períodos 1995 a 1998, 1999 a 2001 e 2002 a 2006. Com base nas inferências feitas pode-se observar que os efeitos competitividade e crescimento do comércio mundial foram os que mais colaboraram para o crescimento das commodities grão, farelo e óleo de soja nos períodos analisados. As inferências deste trabalho foram feitas a partir de dados coletados junto ao Sistema de Análise das Informações de Comércio Exterior (Alice), da Secretaria de Comércio Exterior (Secex), à Food and Agriculture Organization of the United $\mathrm{Na}$ tions (FAO) e à Organização Mundial do Comércio (OMC). Com base nos resultados encontrados pode-se afirmar que Brasil tem uma importância significativa no comércio mundial de soja e apresenta condições edafoclimáticas favoráveis ao aumento da produção.
\end{abstract}

* Artigo recebido em 11 de julho de 2008 e aprovado em 11 de agosto de 2009.

** Doutorando em Economia Aplicada pela Universidade Federal de Viçosa (UFV), mestre em Agronegócios pela Universidade Federal do Rio Grande do Sul (UFRGS), economista pela Universidade Federal de Santa Maria (UFSM) e bolsista de Doutorado da Coordenação de Pessoal de Nível Superior (Capes), e-mail: daniel.coronel@ufv.br

*** Professor adjunto do Departamento de Ciências Econômicas e dos Programas de Pós-graduação em Agronegócios e de Desenvolvimento Rural e coordenador do Programa de Pós-graduação em Agronegócios da UFRGS, e-mail: joao.dessimon@ufrgs.br

**** Professora associada do Departamento de Economia Rural e do Programa de Pós-graduação em Economia Aplicada da UFV, e-mail: fmac@ufv.br 
Palavras-chave: fontes de crescimento; competitividade internacional; agronegócio da soja

Código JEL: Q17 - Agriculture in International Trade; Q13 - Agricultural Markets and Marketing; Cooperatives; Agribusiness; C02 - Mathematical Methods

\section{ANALYSIS OF THE EXPORTS COMPETITIVENESS OF THE COMPLEX SOY BRAZILIAN FROM 1995 TO 2006: AN APPROACH OF MARKET-SHARE}

ABSTRACT This study has the aim of identifying the behavior of the Brazilian soy complex exports from 1995 to 2006. For this, it was used the model of international commerce Constant-Market-Share from 1995 to 1998, 1999 to 2001 and 2002 to 2006 . Based on the interferences done, it was observed that the effects competitiveness and growth of the world-wide commerce collaborated a lot for the commodities growth grain, bran and oil soy in the analyzed periods. The analyses of this paper were done through collected data from the System of Analysis of Information of the Exterior Commerce (Alice), the General Office of Exterior Commerce (Secex), the Food and Agriculture Organization of the United Nations (FAO) and the World-wide Organization of the Commerce (WTO). Based on the considered result, it is possible to infer that Brazil is significantly important in the worldwide commerce of soy and presents favorable soil and climatic conditions to the increase of the production.

Key words: growth sources; international competitiveness; soy agribusiness 


\section{INTRODUÇÃO}

Os mercados internacionais de grande parte das commodities agrícolas possuem uma estrutura bastante complexa. Subsídios à produção agrícola, fornecidos pelos países desenvolvidos, e barreiras tarifárias e não tarifárias fazem com que esses mercados sejam caracterizados, comumente, por competição imperfeita, em menor ou maior grau.

Condições naturais favoráveis, intervenções governamentais, intermediações comerciais e acordos internacionais fazem com que algumas commodities agrícolas sejam mais vantajosamente produzidas em alguns poucos países e consumidas, posteriormente, em toda a parte do mundo. Essa situação permite que pequeno número de países ou até mesmo um único país domine as exportações no mercado internacional, potencializando o exercício do poder de mercado.

Os mercados internacionais de grão, farelo e óleo de soja são exemplos de segmentos concentrados em que Argentina, Brasil e Estados Unidos apresentam poder de mercado, ou seja, podem aumentar lucrativamente o preço de seu produto por meio da redução da quantidade produzida deste (Coronel et al., 2009).

Nos últimos anos, a Argentina vem consolidando a sua liderança nas exportações de farelo, uma vez que os Estados Unidos aumentaram o consumo interno de farelo de soja e o Brasil vem privilegiando as exportações do grão, desde a implantação da Lei Complementar no 87, de 13 de setembro de 1996, mais conhecida como Lei Kandir, que desonerou do Imposto sobre Circulação de Mercadorias (ICMS) as exportações de produtos in natura.

Nesse contexto, alguns trabalhos têm procurado avaliar os preços internacionais do complexo soja, seus impactos ambientais e sociais, sua estrutura competitiva e o Market-Share, merecendo destaque os trabalhos de Sampaio, Sampaio e Costa (2006) e Coronel et al. (2008).

Seguindo essa temática, o presente estudo objetiva identificar as principais fontes de crescimento das exportações brasileiras do complexo soja, de 1995 a 2006, por meio do modelo Constant-Market-Share (CMS).

O presente trabalho está estruturado em quatro seções, além desta introdução. Na segunda seção, tecem-se algumas considerações sobre a evolução 
das exportações brasileiras de grão, farelo e óleo de soja; na terceira, são apresentados os procedimentos metodológicos e descrito o modelo CMS, que permite decompor as fontes de crescimento das exportações; na quarta os resultados obtidos são analisados e discutidos e, finalmente, são apresentadas algumas considerações sobre o estudo.

\section{EVOLUÇÃO DAS EXPORTAÇÕES BRASILEIRAS DE 1995 A 2008}

\subsection{Soja em grão}

De acordo com a FAO (2009), os maiores exportadores mundiais de soja em grão são Estados Unidos, Brasil e Argentina, os quais em conjunto são responsáveis por aproximadamente $85 \%$ das exportações mundiais. O Brasil exportou, em 2008, conforme tabela 1, 24.499.490 toneladas, sendo a taxa geométrica média de crescimento das exportações, de 1995 a 2008, de aproximadamente $16 \%$ ao ano.

Um dos fatores que impulsionaram as exportações de soja em grão foi a Lei Kandir, que desonerou as exportações de produtos in natura do Imposto sobre Circulação de Mercadorias (ICMS), embora, por outro lado, venha desestimulando a venda de produtos que poderiam ter maior valor agrega-

Tabela 1: Evolução das exportações brasileiras de soja em grão (em toneladas) de 1995 a 2008

\begin{tabular}{ll}
\hline Ano & Exportação de soja em grão \\
\hline 1995 & 3.495 .585 \\
\hline 1996 & 3.647 .048 \\
\hline 1997 & 8.339 .824 \\
\hline 1998 & 9.274 .911 \\
\hline 1999 & 8.917 .352 \\
\hline 2000 & 11.517 .337 \\
\hline 2001 & 15.675 .587 \\
\hline 2002 & 15.970 .490 \\
\hline 2003 & 19.890 .467 \\
\hline 2004 & 19.247 .690 \\
\hline 2005 & 22.435 .072 \\
\hline 2006 & 24.957 .975 \\
\hline 2008 & 23.733 .774 \\
\hline Fonte: Organização dos autores a partir de dados do Mapa.
\end{tabular}


do, como farelo e óleo. Outro fator que colaborou para o crescimento das exportações não só do grão, mas do complexo soja, foi a desvalorização cambial de 1999, conforme pesquisa de Coronel et al. (2008).

Os maiores importadores da soja brasileira são os países pertencentes à União Europeia, com destaque para Holanda, Alemanha e Espanha, e China e Japão. Um dos grandes desafios que o governo brasileiro enfrenta são as barreiras tarifárias e não tarifárias que os principais importadores de soja impõem (Secex, 2008).

Ainda segundo a Secex (2008), a China impõe uma taxa de 3\%, desde 2001, para as importações de soja preta, verde e outros grãos de soja. Antes de 2001, essas tarifas tiveram picos de 114\%. Além disso, a China sempre recorreu a barreiras não tarifárias às importações, tais como cotas, inspeções aduaneiras, restrições quantitativas, licenças para importar, certificações restritivas e padrões de quarentena. Outra dificuldade que o exportador enfrenta refere-se aos preços do mercado chinês, visto que há três tipos: o preço estatal, o preço de orientação estatal, que tem relação direta com a economia chinesa, e o regulado pelo mercado.

Em 2004, o Brasil sofreu restrições por parte da China, que exigia a certificação do grão devido aos produtos geneticamente modificados e, posteriormente, devido à presença de grãos com ferrugem. Fernandes et al. (2005), ao analisarem os aspectos que levaram a China a quebrar contratos com o Brasil, em 2004, por causa da ferrugem, afirmam que a incidência de ferrugem, que era de $0,06 \%$, estava dentro dos padrões permitidos pela Organização Mundial do Comércio (OMC), que é de $0,2 \%$ por tonelada, tendo a China se utilizado de barreiras não tarifárias com o pretexto de justificar tal atuação como benéfica à saúde da população. Como resultado, os exportadores brasileiros, para não perderem os vários carregamentos, tiveram de se ajustar às exigências chinesas e ainda baixaram os preços.

Ainda segundo esses autores, a China sempre recorreu a barreiras para proteger seus produtos; contudo, com o ingresso desse país na OMC, suas práticas protecionistas tendem a diminuir.

O Japão tem uma estrutura tarifária que apresenta progressividade à medida que os produtos adquirem maior valor agregado. Assim, a tarifa de importação da soja em grão é zero, enquanto a do óleo é de 20,7 ienes por quilograma (Secex, 2008). 


\subsection{Farelo de soja}

Os maiores exportadores de farelo de soja são Argentina, Estados Unidos e Brasil, os quais em conjunto são responsáveis por aproximadamente $60 \%$ das exportações mundiais, sendo, no segmento de farelo e óleo de soja, a liderança da Argentina, a qual vem priorizando as exportações desses dois segmentos por meio de políticas específicas.

O Brasil exportou, em 2008, conforme tabela 2, 12.287.895 toneladas de farelo, sendo a taxa geométrica média de crescimento, de 1995 a 2008, de 2,0\%, bem abaixo do crescimento médio anual do grão e do óleo. De acordo com Siqueira (2004), as exportações brasileiras de farelo de soja foram afetadas significativamente pela Lei Kandir, visto que o crescimento médio anual das exportações dessa commodity ficou muito aquém das exportações da década de 1980 .

Os maiores importadores do farelo de soja brasileiro, de 1995 a 2008, foram União Europeia (com destaque para Holanda, França, Itália e Alemanha) e países asiáticos, como Tailândia e China. Além desses, é importante destacar que, desde o final da década de 1990, a Indonésia vem se configurando como um promissor mercado para as exportações brasileiras de farelo, conforme Secex (2008).

Tabela 2: Evolução das exportações brasileiras farelo (em toneladas) de 1995 a 2008

\begin{tabular}{lc}
\hline Ano & Exportação de soja em grão \\
\hline 1995 & 11.596 .510 \\
\hline 1996 & 11.261 .698 \\
\hline 1997 & 10.01 .335 \\
\hline 1998 & 10.447 .984 \\
\hline 1999 & 10.430 .878 \\
\hline 2000 & 9.363 .590 \\
\hline 2001 & 11.269 .578 \\
\hline 2002 & 12.517 .160 \\
\hline 2003 & 13.602 .158 \\
\hline 2004 & 14.485 .623 \\
\hline 2006 & 14.421 .679 \\
\hline 2007 & 12.332 .350 \\
\hline 2008 & 12.474 .182 \\
\hline Fonte: Organização dos autores a partir de dados do Mapa.
\end{tabular}




\section{3 Óleo de soja}

Os maiores exportadores de óleo de soja, de acordo com a FAO (2009), são Argentina, Brasil e Estados Unidos, países que, em conjunto, são responsáveis por aproximadamente $71 \%$ das exportações dessa commodity.

As exportações brasileiras de óleo de soja, em 2008, foram de 2.315.837 toneladas, conforme tabela 3 , sendo a taxa geométrica média de crescimento, de 1995 a 2008, de aproximadamente $6,00 \%$ ao ano.

Os maiores importadores do óleo de soja brasileiro, de 1995 a 2008, foram China, Irã, Índia e União Europeia. Esta última vem reduzindo gradativamente as importações de óleo, visto que está intensificando o processamento dessa commodity. Conforme a Secex (2008), o país da União Europeia que mais importa óleo é a Alemanha. Destaca-se ainda que, desde o final da década de 1990, Egito, Blangladesh e Marrocos vêm se configurando como importantes mercados para as importações do óleo produzido no Brasil.

Um dos grandes obstáculos que os exportadores brasileiros de óleo enfrentam está relacionado às barreiras que os principais mercados impõem.

As tarifas de óleo para a China têm alíquotas de 9\%; contudo, antes da entrada desse país na OMC, essas tarifas eram de 74,14\%, e em alguns pe-

Tabela 3: Evolução das exportações brasileiras de óleo de soja

(em toneladas) de 1995 a 2008

\begin{tabular}{ll}
\hline Ano & Exportação de soja em grão \\
\hline 1995 & 1.763 .958 \\
\hline 1996 & 1.332 .256 \\
\hline 1997 & 1.125 .891 \\
\hline 1998 & 1.366 .888 \\
\hline 1999 & 1.550 .760 \\
\hline 2000 & 1.072 .994 \\
\hline 2001 & 1.651 .525 \\
\hline 2002 & 1.934 .386 \\
\hline 2004 & 2.485 .986 \\
\hline 2005 & 2.517 .243 \\
\hline 2006 & 2.697 .054 \\
\hline 2007 & 2.419 .378 \\
\hline 2008 & 2.342 .521 \\
\hline Fonte: Organização dos autores a partir de dados do Mapa.
\end{tabular}


ríodos tiveram picos em torno de $120 \%$. Além disso, a China exige dos exportadores de óleos certificados e rótulos que acabam dificultando as exportações.

As tarifas para o óleo bruto que a União Europeia impõe são de 3,8\% para o uso industrial e 7,6\% para o uso comercial; já para o óleo refinado são de $6,1 \%$ para o uso comercial e 11,4\% para o uso industrial. Não obstante e de acordo com a Secex (2008), a perspectiva de essas barreiras caírem é elevada caso seja efetivado o acordo entre a União Europeia e o Mercosul, o que poderá beneficiar os exportadores brasileiros.

Além disso, outros obstáculos às exportações estão relacionados à Política Agrícola Comum da União Europeia, que subsidia diretamente os produtores com diversos programas; adota o Princípio de Preferência Comunitária, que procura assegurar a prioridade para o consumo de produtos comunitários com princípios com proteção contra importações; prevê o aumento da produtividade agrícola mediante o desenvolvimento racional da agricultura; assegura um nível de vida digno aos produtores agrícolas; estimula os mercados agrícolas; garante um abastecimento regular em produtos alimentícios; e assegura preços razoáveis aos consumidores (Secex, 2008).

\section{METODOLOGIA}

\subsection{Modelo Constant-Market-Share}

Segundo Coronel (2008), os trabalhos baseados em modelos ConstantMarket-Share têm como objetivo avaliar a participação de um país ou região no fluxo mundial ou regional de comércio e desagregar as tendências de crescimento das exportações e/ou importações de acordo com seus determinantes. Nesse sentido, o modelo CMS tem sido utilizado para análises da determinação dos fatores que contribuíram para o desempenho das exportações de um país ou bloco econômico em determinado período.

O pressuposto básico do modelo é que cada país ou bloco mantêm constante sua parcela no comércio mundial. Se houver alteração nessa parcela, ela deve estar implícita no modelo, e sua performance é atribuída à competitividade, associada aos preços relativos (Leamer; Stern, 1970).

No entendimento de Leamer e Stern (1970), os fatores que colaboram para que as exportações de um país não acompanhem a média mundial são 
concentração das exportações em mercadorias cuja demanda cresça mais lentamente que a média dos produtos; exportações destinadas a regiões estagnadas; e falta de condições de o país competir com os seus concorrentes no mercado internacional. Esses autores consideram que a relação de preços de dois países exportadores no comércio internacional determina a escolha dos países importadores, o que pode ser escrito da seguinte forma:

$$
\frac{q_{1}}{q_{2}}=f\left(\frac{p_{1}}{p_{2}}\right) \operatorname{com} \mathrm{f}^{\prime}<0
$$

A equação (1) é oriunda da relação básica da elasticidade de substituição, onde $q_{1}$ e $q_{2}$ são as quantidades vendidas pelos exportadores 1 e 2 e $p_{1}$ e $p_{2}$, seus respectivos preços. A equação (1) pode ser representada na forma de market-share, multiplicando-a por $\frac{p_{1}}{p_{2}}$.

$$
\frac{p_{1} q_{1}}{p^{2} q^{2}}=\frac{p^{1}}{p^{2}} * f\left(\frac{p^{1}}{p^{2}}\right)
$$

Rearranjando-se os termos, tem-se:

$$
\frac{p_{1} q_{1}}{p_{1} q_{1}+p_{2} q_{2}}=\left(1+\frac{p_{2} q_{2}}{p_{1} q_{1}}\right)^{-1}=\left\{1+\left[\frac{p_{1}^{*} f\left(\frac{p_{1}}{p_{2}}\right)}{p_{2}}\right]^{-1}\right\}^{-1}=g\left(\frac{p_{1}}{p_{2}}\right) \operatorname{com} g^{\prime}<0
$$

A equação (3) indica que o market-share do país permanece constante, caso não haja alterações nos preços relativos, $\frac{p_{1}}{p_{2}}$ representando o princípio do modelo Constant-Market-Share para um determinado período de tempo. Se o país não mantiver sua parcela no mercado mundial, o termo poderá ser negativo, indicando que os preços estão subindo mais rapidamente para o país em questão em relação aos seus concorrentes no mercado internacional.

Leamer Stern (1970) e Richardson (1971), utilizando-se do instrumental matemático, decompuseram as taxas de crescimento das exportações em 
quatro efeitos, a saber, crescimento do comércio internacional, composição da pauta de exportações, destino das exportações e competitividade.

A forma mais simples do CMS define que a parcela de mercado de um país depende de sua competitividade relativa. Isso pode ser mais bem observado na equação (4):

$$
\frac{S}{Q} \equiv \frac{q}{C}=f(\mathcal{c}) \quad f(\mathcal{C})>0
$$

onde:

$S$ = parcela de mercado do país em questão;

$q, Q=$ quantidade total exportada pelo país A e pelo mundo, respectivamente;

$c$, $C=$ competitividade do país A e do mundo, respectivamente.

Rearranjando-se os termos e derivando-se em relação ao tempo, tem-se que:

$$
\begin{aligned}
& \frac{d}{d t} \equiv S \frac{d Q}{d t}+Q \frac{d S}{d t} \\
& \dot{q} \equiv S \dot{Q}+Q \dot{S} \\
& \dot{q} \equiv S \dot{Q}+Q f^{\prime}\left(\frac{d\left(\frac{c}{C}\right)}{d t}\right) \\
& \dot{q} \equiv S \dot{Q}+Q f^{\prime}\left(\frac{\dot{c}}{C}\right)
\end{aligned}
$$

De acordo com a identidade (5), a variação total da quantidade exportada do país A $(\dot{q})$ é explicada pelo efeito crescimento das exportações mundiais $(S \dot{Q})$ e pelo efeito competitividade $(\dot{S} Q)$. O primeiro representa o crescimento nas exportações desde que seja mantida constante a parcela do mercado, e o segundo representa o crescimento adicional atribuído às mudanças na competitividade relativa. 
A estrutura das exportações de um país pode estar afetando sua competitividade, ainda que não ocorram mudanças na competitividade relativa. $\mathrm{O}$ país pode estar concentrando suas exportações em mercadorias cuja demanda está crescendo mais rapidamente ou destinando-se às regiões de crescimento mais dinâmico.

Nesse sentido, a identidade (5) ficaria:

$$
\operatorname{Sij} \equiv \frac{q_{i j}}{Q_{i j}}=f_{i j}\left(\frac{c_{i j}}{C_{i j}}\right) f^{\prime}{ }^{\prime i j}>0
$$

onde:

$i=$ mercadoria comercializada pelo país A; e

$j=$ mercado de destino.

Nesse sentido, o crescimento total das exportações passa a ser dado por

$$
q \equiv \sum_{i} \sum_{j} S_{i j} \dot{Q}_{i j}+\sum_{i} \sum_{j} Q_{i j} \dot{S}_{i j}
$$

Conforme Richardson (1971), expandindo-se, tem que:

$$
\underset{\text { q }}{\dot{q}} \equiv S_{\text {(a) }}+\left[\sum_{i} S_{i} \dot{Q}_{i}-S \dot{Q}\right]+\left[\sum_{i} \sum_{j} S_{i j} \dot{Q}_{i j}-\sum_{i} S_{i} \dot{Q}_{i}\right]+\sum \sum Q_{i j} \dot{S}_{i j}
$$

(a)

A identidade (8) mostra que o crescimento das exportações é decomposto no crescimento das exportações mundiais, favorável ou desfavorável, associado à estrutura das mercadorias ou mercados e às mudanças na competitividade relativa. $\mathrm{O}$ termo indica (a) o efeito crescimento do mercado, (b) o efeito mercadoria, (c) o efeito mercado e (d) o efeito competitividade. O efeito competitividade, quando associado apenas às alterações nos preços relativos, indica que os países ou as regiões importadoras tendem a substituir o consumo de mercadorias que se tornam mais caras por aqueles cujos preços se tornam relativamente mais baixos.

Para representar matematicamente o modelo Constant-Market-Share, faz-se necessário considerar como variável básica o valor das exportações. Primeiramente, parte das exportações não diferenciadas por mercadorias e regiões, de modo que se pode escrever a seguinte identidade:

$$
V^{\prime} . .-V . . \equiv r V+\left(V^{\prime} . .-V . .-r V . .\right)
$$


onde:

$V . .=$ valor total das exportações do país ou região A, no período (I);

$V^{\prime} . .=$ valor total das exportações do país ou região A, no período (II);

$r=$ mudança percentual nas exportações mundiais do período (I) para o período (II).

A identidade (9) expressa que a variação das exportações do país ou região A, do período (I) para o período (II), está associada ao incremento das exportações mundiais (a) e a um efeito residual atribuído à competitividade (b). Essa expressão é análoga à (5).

De acordo com Richardson (1971), as exportações são compostas por um conjunto diverso de mercadorias. Assim, tem-se para a i-ésima mercadoria uma expressão equivalente a (9), ou seja:

$$
V^{\prime}{ }_{i .}-V_{i .} \equiv r_{i} V_{i .}+\left(V_{i .}^{\prime}-V .-r_{i} V_{i .}\right)
$$

onde:

$V_{i .}=$ valor das exportações da mercadoria do país ou região A, no período (I);

$V^{\prime}{ }_{i}=$ valor das exportações da mercadoria do país ou região A, no período (II);

$r_{i}=$ mudança percentual nas exportações mundiais da mercadoria para o país ou região (j) do período (I) para o período (II).

A expressão (10) pode ser agrupada em:

$$
V_{i . .}^{\prime}-V_{i . .} \equiv r_{i} V_{i .}+\left(V_{i .}^{\prime}-V_{i .}-r_{i} V_{i .} \equiv\left(r V_{. .}\right)+\sum_{i}\left(r_{i}-r\right) V_{i .}+\sum_{i}\left(V_{i .}^{\prime}-V_{i .}-r_{i} V_{i .}\right)\right.
$$

Com base na equação (10), pode-se inferir que o crescimento das exportações do país A está relacionado com (a) crescimento das exportações mundiais, (b) pauta das exportações do país ou região A no período (I) e ao efeito residual oriundo da diferença entre a variação efetiva e a variação esperada nas exportações de cada grupo de bens.

Ainda nessa perspectiva, a desagregação do modelo Constant-MarketShare considera tanto a diferenciação por tipo de mercadoria comercializa- 
da quanto aquela por países ou regiões de destino ( $j$ ). Nesse sentido, ao considerar a diferenciação das exportações por destino e por tipo de mercadoria, chega-se à seguinte expressão:

$$
V^{\prime}{ }_{i j}-V_{i j} \equiv r_{i j} V_{i j}+\left(V_{i j}^{\prime}-V_{i j}-r_{i j}-V_{i j}\right)
$$

onde:

$V_{i j}=$ valor das exportações da mercadoria (i) do país ou região A para o país ou região $(j)$ no período $(\mathrm{I})$;

$V^{\prime}{ }_{i j}=$ valor das exportações da mercadoria $(i)$, do país ou região A para o país ou região (j) no período (II);

$r_{i j}=$ mudança percentual nas exportações mundiais da mercadoria $(i)$ para o país ou região $(j)$ do período (I) para o período (II).

Desagrupando e reajeitando os termos, tem-se a seguinte identidade (13):

$$
\begin{aligned}
& V^{\prime} . .-V \sum_{i} \sum_{j} r_{i j} V_{i j}+\sum_{i} \sum_{j}\left(V_{i j}^{\prime}-V_{i j}-r_{i j} V_{i j}\right) \equiv r V . .+\sum_{i}(r i-r) V_{i .}+ \\
& \sum_{i} \sum_{j}\left(r_{i j}-r_{i}\right) V_{i j}+\sum_{i} \sum_{j}\left(V^{\prime}{ }_{i j}-V_{i j}-r_{i j} V_{i j}\right) \\
& \text { (c) (d) }
\end{aligned}
$$

A identidade (13) permite decompor a taxa de crescimento das exportações do país A em quatro efeitos, a saber:

O efeito composição da pauta (b), $\sum_{i}\left(r_{i}-r\right) V_{i}$. indica que, se as exportações mundiais do produto ( $i$ ) aumentarem mais que a média mundial para todas as mercadorias exportadas, $\left(r_{i}-r\right)$ é positivo. O resultado tornará forte esse efeito se $V_{i}$ for relativamente grande, ou seja, o efeito composição da pauta será positivo se as exportações do país A estiverem concentradas no produto de maior expansão ou quando a taxa de crescimento for superior à média mundial.

O efeito destino das exportações será positivo (c) $\sum_{i} \sum_{j}\left(r_{i j}-r_{i}\right) V_{i j}$ se o país A tiver concentrado suas exportações em mercados que experimentaram maior dinamismo no período analisado e negativo se concentrado em regiões mais estagnadas. 
O efeito competitividade (d) $\sum_{i} \sum_{j}\left(V^{\prime}{ }_{i j}-V_{i j}-r_{i j} V_{i j}\right)$ significa que uma economia é competitiva na produção de determinada commodity quando consegue pelo menos igualar-se aos padrões de eficiência vigentes no resto do mundo quanto à utilização de recursos e à qualidade do bem. A diferença entre o crescimento das exportações verificado pelo modelo CMS e o crescimento efetivo das exportações é atribuída ao efeito competitividade. A medida desse efeito está relacionada com mudanças nos preços relativos $\frac{p_{1}}{p_{2}}$. Nesse sentido, quando um país deixa de manter sua parcela no mercado mundial, o termo competitividade torna-se negativo e indica o fracasso do país em manter sua parcela no mercado mundial, bem como também que os preços estão aumentando para o país em questão, em proporção maior que seus competidores, ou seja, os importadores tendem a substituir o consumo das commodities cujos preços se elevaram pelo consumo daqueles com preços menores em termos relativos.

Conforme Leamer e Stern (1970), o efeito competitividade, além dos preços relativos, recebe influência de outros fatores, tais como mudanças tecnológicas, medidas de incentivo, maiores ações de marketing, aprimoramento dos mecanismos de financiamento e crédito e habilidade para atender com prontidão às encomendas dos importadores.

\subsection{Mercado de destino}

Consideraram-se, neste trabalho, para fins de análise, os mercados que absorveram a maior parte das exportações brasileiras do complexo soja:

(a) soja em grão: União Europeia, China, Japão e resto do mundo (representando os demais importadores);

(b) farelo de soja: União Europeia, China, Tailândia e resto do mundo (representando os demais importadores); e

(c) óleo de soja: China, Irã, Índia, União Europeia e resto do mundo (representando os demais importadores).

\subsection{Período de análise}

Como o modelo CMS é fixado em pontos discretos no tempo, foi necessário dividir os dados em períodos. Coronel (2008) ressalta que, visto que as ex- 
portações sofrem mudanças ao longo do tempo, a divisão em períodos mais curtos permite verificar com maior segurança as alterações mais frequentes que ocorreram entre um dado período analisado.

Dessa forma, dividiu-se o período nos seguintes subperíodos:

(a) 1995 a 1998 = primeiro período: representa a fase de estabilização da economia brasileira, a sobrevalorização cambial e seus impactos no setor exportador;

(b) 1999 a 2001 = segundo período: representa a etapa de alavancagem das exportações do setor agroindustrial brasileiro;

(c) 2002 a 2006 = terceiro período: representa os anos mais recentes do crescimento das exportações do complexo soja.

\subsection{Fonte de dados}

Os dados para o cálculo do modelo Constant-Market-Share foram coletados junto ao Sistema de Análise das Informações de Comércio Exterior (Alice), da Secretaria de Comércio Exterior (Secex), que possui os dados de exportações brasileiras Free on Board (FOB) em dólares, à Food and Agriculture Organization of the United Nations (FAO) e à Organização Mundial do Comércio (OMC).

Os dados relativos às exportações totais brasileiras bem como os das exportações totais brasileiras de soja e por mercado de destino foram coletados junto à Secex; os dados das exportações mundiais de soja foram obtidos junto à $\mathrm{FAO}$ e os das exportações mundiais, junto à OMC.

\section{ANÁLISE E DISCUSSÃO DOS RESULTADOS}

\subsection{Decomposição das fontes de crescimento das exportações de soja em grão}

\subsubsection{Período II em relação ao período I}

O Brasil, entre 1995 e 1998, período I, era responsável por 17\% das exportações mundiais de soja em grão, participação que foi crescente, no período II (1999-2001), sendo responsável por 24\% das exportações mundiais e, no período III (2002-2006), por 32\% das exportações, ou seja, em todo o período analisado, o país aumentou sua participação no mercado mundial de soja em grão. 
Tabela 4: Valor médio das exportações mundiais e brasileiras de soja em grão, em US\$ FOB, e participação do Brasil nas exportações mundiais de soja em grão (1995-2006)

\begin{tabular}{lccc}
\hline & $1995 / 1998$ & $1999 / 2001$ & $2002 / 2006$ \\
\hline Exportações mundiais & 9.433 .181 .000 & 9.078 .605 .333 & 14.770 .475 .400 \\
\hline Exportações brasileiras & 1.604 .811 .351 & 2.168 .893 .250 & 4.745 .161 .000 \\
\hline Market-share (\%) & 17 & 24 & 32 \\
\hline
\end{tabular}

Fonte: Organização dos autores a partir de dados da FAO e Secex.

Tabela 5: Fontes de crescimento das exportações brasileiras de soja em grão (1995-2006)

\begin{tabular}{lcc}
\hline & $1995 / 1998$ a 1999/2001 (\%) & 1999/2001 a 2002/2006 (\%) \\
\hline Crescimento do comércio mundial & $-3,00$ & 55,00 \\
\hline Destino das exportações & $-20,00$ & $-8,00$ \\
\hline Competitividade & 123,00 & 53,00 \\
\hline Fonte: Organização dos autores a partir de dados da FAO e Secex.
\end{tabular}

Fonte: Organização dos autores a partir de dados da FAO e Secex.

As análises das exportações brasileiras de soja em grão do período II em relação ao período I indicam que os maiores importadores da soja em grão foram União Europeia, China e Japão.

O efeito que mais contribuiu para as exportações brasileiras de soja em grão foi a competitividade, conforme a tabela 5, com 123\%, sendo os efeitos crescimento do comércio mundial e destino das exportações negativos, ou seja, se fosse mantida constante a participação do Brasil no mercado mundial de soja em grão, as exportações teriam sido superiores na ausência desses dois últimos efeitos.

O efeito competitividade reflete um conjunto de fatores que, dadas as limitações desse modelo, fogem ao escopo do trabalho, mas é possível fazer algumas inferências com base em variáveis que podem ter exercido influência. Dentre elas, pode-se destacar a estabilidade econômica que o país começou a apresentar a partir da implantação do Plano Real, quando se observam baixas taxas de inflação.

Outro fator que contribuiu de maneira fundamental para o forte efeito competitividade foi a Lei Kandir, de 1996, que, ao desonerar do Imposto sobre Circulação de Mercadorias e Serviços (ICMS) os produtos primários e semielaborados, estimulou as exportações de soja em grão.

A competitividade da soja em grão, como também de outros produtos do agronegócio brasileiro, foi favorecida pela desvalorização cambial, a par- 
tir de 1999, que possibilitou aos produtos do agronegócio brasileiro terem maior competividade no mercado internacional.

Cassuce e Santos (2005), utilizando-se da Abordagem das Elasticidades e dos Modelos Autorregressivos Estruturais, concluíram que as desvalorizações cambiais de fato elevaram o valor, em divisas, das exportações brasileiras de soja em grão.

Algumas variáveis internas também estão relacionadas ao efeito competividade, como a Cédula do Produtor Rural, que, além de fornecer liquidez ao produtor, assegurou os preços. Conforme Figueiredo e Santos (2005), isso foi aperfeiçoado com a Cédula do Produtor Rural Financeira, visto que o produtor não deixa de ganhar se os preços estiverem acima do preço previsto na data de vencimento da cédula. Também merece destaque o Programa de Modernização da Frota de Tratores Agrícolas e Implementos Associados e Colheitadeiras (Moderfrota), criado em 2000, fundamental para a modernização do agronegócio brasileiro.

A competitividade da soja em grão também foi favorecida pelo aumento da produtividade e produção nos últimos anos, principalmente na Região Centro-Oeste. De acordo com o Ministério da Agricultura, Pecuária e Abastecimento (Mapa, 2008), essa região firmou-se como a maior produtora da oleaginosa no país, na década de 1990.

Ainda nessa perspectiva, merece destaque que a competitividade da soja brasileira também foi favorecida pelas novas tecnologias de sementes desenvolvidas por instituições como a Empresa Brasileira de Pesquisa Agropecuária (Embrapa), tais como as sementes geneticamente modificadas.

Por outro lado, o efeito destino das exportações, que foi negativo, indica que as exportações brasileiras de soja em grão não estão se concentrando em mercados muito dinâmicos, ou seja, o Brasil está direcionando suas exportações para mercados menos dinâmicos que a média do comércio mundial. Esse resultado só não foi maior possivelmente pelo aumento das exportações brasileiras de soja em grão para a China, mercado em expansão, a partir da segunda metade da década de 1990, conforme trabalhos de Ilha e Coronel (2006) e Coronel et al. (2009).

Outro fator que pode ter contribuído para que o efeito destino das exportações fosse negativo foram os subsídios americanos à soja, que, em 1993, eram de US\$ 109 milhões e, em 2000, eram de aproximadamente 
US\$ 2,84 bilhões, conforme dados da Confederação Nacional da Agricultura (CNA, 2008). Esses subsídios, podem gerar distorções no comércio mundial, promovendo aumentos artificiais na oferta mundial, capazes de induzir relações nos níveis de preços internacionais, tornando menos vantajoso para seus concorrentes colocar seus produtos em mercados com demandas relativamente mais elásticas, ou impossibilitando-os de fazê-lo (Figueiredo, Santos e Lírio, 2004).

O efeito comércio mundial, apesar de ser negativo, não foi alto, em valor absoluto, podendo estar relacionado à retração nas exportações mundiais de soja, que ocorreu entre 1999 e 2001.

\subsubsection{Período III em relação ao período II}

Quando se analisa o terceiro período em relação ao segundo, observa-se que o efeito competitividade continuou sendo importante, mas reduziu-se, sendo responsável por aproximadamente $53 \%$ das exportações de soja em grão.

Essa redução do efeito competitividade pode estar relacionada à sobrevalorização cambial, do período 2003/2004, conforme pesquisa de Coronel (2008). Ainda nessa perspectiva, de acordo com Souza et al. (2007), que estudaram a relação das mudanças cambiais com as exportações brasileiras de soja, a sobrevalorização cambial que começou a ocorrer a partir de $2003 \mathrm{fez}$ com que o complexo soja aumentasse os preços no mercado internacional, perdendo competitividade relativa principalmente para o grão.

O efeito comércio internacional foi positivo, contribuindo com $55 \%$ das exportações; porém, o efeito destino das exportações continuou sendo negativo, reduzindo-se para $8 \%$, ou seja, se fosse mantida constante a participação do Brasil no mercado mundial de soja em grão, as exportações poderiam ter sido superiores na ausência desse efeito.

De acordo com a tabela 5, o efeito crescimento do comércio mundial, que nesse período foi positivo, pode ser explicado pelo seguinte fator: um aumento significativo da demanda de grãos pela China, como parte de uma estratégia do governo chinês, que prioriza a importação de produtos in natura, com menor valor agregado como forma de valorizar o processamento interno (Coronel et al., 2008). Outro fator que também pode ter colaborado para esse resultado foi um aumento nas exportações mundiais de soja em grão, de 2002 a 2004, conforme a FAO (2009). 
O efeito destino das exportações, apesar de negativo, melhorou se comparado ao período anterior, já que antes era de $-20 \%$ e, nesse período, foi de $-8 \%$, indicando ainda que o Brasil continuou direcionando suas exportações de soja em grão para mercados menos dinâmicos que a média do comércio mundial.

\subsection{Decomposição das fontes de crescimento das exportações de farelo de soja}

\subsubsection{Período II em relação ao período I}

De acordo com a tabela 6, o Brasil, no primeiro período (1995 a 1998), era responsável por 30\% das exportações mundiais de farelo, mas diminuiu sua participação no período II (1999-2001) para 25\% e, no período III (2002 a 2006), o país apresentou novo crescimento, passando a ser responsável por $27 \%$.

As análises das exportações de farelo de soja indicam que, em todo o período analisado, os maiores importadores do produto brasileiro foram a União Europeia, a Tailândia e a China, sendo a União Europeia responsável por aproximadamente $80 \%$ das importações, o que mostra uma elevada concentração nesse mercado.

A decomposição das fontes de crescimento do farelo de soja, do período II em relação ao período I, indica que os efeitos competitividade e destino das exportações foram positivos e o efeito comércio mundial foi negativo,

\section{Tabela 6: Valor médio das exportações mundiais e brasileiras de farelo de soja, em US\$}

FOB, e participação do Brasil nas exportações mundiais de farelo de soja (1995-2006)

\begin{tabular}{lccc}
\hline & $1995 / 1998$ & $1999 / 2001$ & 2002/2006 \\
\hline Exportações mundiais & 7.406 .110 .485 & 6.943 .687 .567 & 10.486 .451 .400 \\
\hline Exportações brasileiras & 2.290 .513 .598 & 1.739 .046 .197 & 2.890 .709 .839 \\
\hline Market-share (\%) & 30 & 25 & 27 \\
\hline
\end{tabular}

Fonte: Organização dos autores a partir de dados da FAO e Secex.

Tabela 7: Fontes de crescimento das exportações brasileiras de farelo de soja (1995-2006)

\begin{tabular}{lcc}
\hline & $1995 / 1998$ a 1999/2001 (\%) & 1999/2001 a 2002/2006 (\%) \\
\hline Crescimento do comércio mundial & $-8,41$ & 104,25 \\
\hline Destino das exportações & 12,71 & $-18,90$ \\
\hline Competitividade & 95,70 & 14,65 \\
\hline Fonte: Organização dos autores a partir de dados da FAO e Secex.
\end{tabular}

Fonte: Organização dos autores a partir de dados da FAO e Secex. 
ou seja, se a participação do Brasil no mercado mundial de farelo de soja fosse mantida constante, as exportações teriam sido superiores na ausência desse efeito (tabela 7).

A competitividade foi o fator que mais contribuiu para as exportações de farelo de soja, com aproximadamente 95,7\%. Conforme já destacado, vários fatores favorecem o efeito competitividade, mas, no caso do farelo de soja, podem-se citar: a estabilização econômica da economia brasileira, com baixas taxas de inflação a partir da implantação do Plano Real, e a desvalorização cambial a partir de 1999, que favoreceu todo o complexo soja, como mostram Fraga et al. (2008).

Favoreceram ainda a competitividade da soja as políticas governamentais Cédula do Produtor Rural, a securitização das dívidas e o Programa de Modernização da Frota de Tratores Agrícolas e Implementos Associados e Colheitadeiras (Moderfrota), fundamental para a modernização do complexo soja.

O efeito destino das exportações contribuiu com $12,71 \%$, indicando que a taxa das importações dos mercados importadores do Brasil está crescendo a taxas maiores que a média do mercado mundial, ou seja, o Brasil está direcionando suas exportações de farelo para mercados mais dinâmicos que a média do comércio mundial. Isso pode ser corroborado pelo seguinte fato: do período II em relação ao período I, as importações mundiais de farelo de soja tiveram um decréscimo de aproximadamente $2,81 \%$, enquanto as importações da União Europeia, o principal mercado importador brasileiro, tiveram um aumento de $7,08 \%$.

O efeito crescimento do comércio mundial foi negativo, e uma das possíveis causas foi o decréscimo de 6,24\% nas exportações mundiais de farelo de 1999 a 2001 em relação ao período de 1995 a 1998.

\subsubsection{Período III em relação ao período II}

A decomposição das fontes de crescimento das exportações brasileiras de farelo de soja, do período III em relação a período II, mostra que o efeito crescimento do comércio mundial foi o principal fator explicativo das exportações brasileiras de farelo de soja, com 104,25\%, e a competitividade continuou sendo fator positivo para as exportações, embora de menor proporção. O efeito destino das exportações foi negativo, ou seja, na ausência desse efeito, as taxas de crescimento das exportações teriam sido maiores. 
O resultado do efeito crescimento do comércio mundial pode ser explicado pelo aumento significativo das exportações mundiais de farelo ocorrido de 2002 a 2006, sendo, o crescimento, superior a 51\% do período II (1999 a 2001).

O efeito competitividade, apesar de continuar sendo positivo, caiu significativamente, e essa queda pode ser explicada pelo fato de os exportadores brasileiros, desde a implantação da Lei Kandir, estarem privilegiando cada vez mais as exportações dos produtos in natura, em detrimento do processamento interno, conforme Sampaio, Sampaio e Costa (2006) e Coronel (2008). Outro fator que contribuiu para a queda da competitividade das exportações do farelo foi o comportamento protecionista de alguns países à medida que os produtos adquiriam maior valor agregado, o que levou os exportadores a privilegiarem os produtos de menor valor agregado, reforçando a vantagem derivada do fator terra, que permite menores custos, onde o país exportador transfere parte de suas vantagens naturais para o mercado importador.

Além disso, de acordo com Coronel (2008), outra variável que influencia para o Brasil perder competitividade nas exportações de farelo de soja está relacionada à inadequação das estruturas de transporte e logística, que vêm se deteriorando cada vez mais no país.

O efeito destino das exportações refletiu negativamente nas exportações de farelo. Isso pode estar relacionado ao fato de que, do período III em relação ao período II, as importações mundiais de soja cresceram 53\%, ao passo que as da União Europeia, o principal mercado importador brasileiro, cresceram 48\%. Além disso, a China e a Tailândia, que, segundo a Secex (2008), são importantes mercados brasileiros, apresentaram os seguintes resultados: a China teve um decréscimo de $77 \%$ e a Tailândia, um crescimento de $46 \%$. Isso significa que as taxas de importação dos principais mercados importadores brasileiros cresceram a taxas menores que as importações mundiais, ou seja, do período III em relação ao período II, o país direcionou suas exportações de farelo para mercados menos dinâmicos que a média do comércio mundial.

De acordo com Sampaio, Sampaio e Costa (2006), a política chinesa de proteção à indústria interna de esmagamento colaborou significativamente para a redução das importações de farelo e óleo. 


\subsection{Decomposição das fontes de crescimento das exportações de óleo de soja}

\subsubsection{Período II em relação ao período I}

O Brasil, no primeiro período (1995 a 1998), era responsável por 20\% das exportações mundiais de óleo de soja, mas diminuiu sua participação nas exportações mundiais no período II (1999-2001) para 16,33\% e, no período III (2002 a 2006), o país apresentou novo crescimento, passando a ser responsável por 22,46\% das exportações mundiais.

As análises das exportações de óleo de soja indicam que, no período analisado, os maiores importadores do óleo de soja brasileiro foram China, Irã, Índia e União Europeia, sendo esses mercados responsáveis por aproximadamente $75 \%$ das exportações brasileiras dessa commodity. As análises evidenciaram que o mercado importador do óleo de soja brasileiro é relativamente menos concentrado que o do grão e farelo de soja.

A decomposição das fontes de crescimento do óleo de soja, do período II em relação ao período I (tabela 9), indica que os efeitos competitividade e comércio mundial foram positivos, e o destino das exportações foi negativo, ou seja, se a participação do Brasil no mercado mundial de óleo de soja fosse mantida constante, as exportações teriam sido superiores na ausência desse efeito.

Tabela 8: Valor médio das exportações mundiais e brasileiras de óleo de soja, em US\$ FOB, e participação do Brasil nas exportações mundiais de óleo de soja (1995-2006)

\begin{tabular}{lccc}
\hline & $1995 / 1998$ & $1999 / 2001$ & 2002/2006 \\
\hline Exportações mundiais & 3.994 .723 .115 & 3.167 .261 .263 & 5.241 .550 .000 \\
\hline Exportações brasileiras & 798.952 .854 & 517.468 .788 & 1.177 .596 .000 \\
\hline Market-share (\%) & 20,00 & 16,33 & 22,46 \\
\hline
\end{tabular}

Fonte: Organização dos autores a partir de dados da FAO e Secex.

Tabela 9: Fontes de crescimento das exportações brasileiras de óleo de soja (1995-2006)

\begin{tabular}{lcc}
\hline & 1995/1998 a 1999/2001 (\%) & 1999/2001 a 2002/2006 (\%) \\
\hline Crescimento do comércio mundial & 10,01 & 78,9 \\
\hline Destino das exportações & $-20,21$ & 3,81 \\
\hline Competitividade & 110,20 & 17,29 \\
\hline
\end{tabular}

Fonte: Organização dos autores a partir de dados da FAO e Secex. 
O efeito competitividade foi o que mais colaborou para as exportações de óleo de soja do período II em relação ao período I, favorecido pela estabilização da economia brasileira, com baixas taxas de inflação a partir da implantação do Plano Real, e a desvalorização cambial a partir de 1999, conforme estudo de Fraga et al. (2008).

O efeito crescimento do comércio mundial foi positivo e contribuiu com $10,01 \%$, sendo esse efeito influenciado pela forte expansão da demanda mundial de óleo, que ocorreu até meados da década de 1990. O efeito comércio mundial possivelmente não foi maior, porque, no período II, de 1999 a 2001, houve uma retração de aproximadamente $20,7 \%$ nas exportações mundiais de óleo soja, em relação ao período I (1995 a 1998).

$\mathrm{O}$ efeito destino das exportações refletiu negativamente nas exportações brasileiras de óleo de soja, ou seja, estas cresceram mais para mercados menos dinâmicos que os outros países do mundo. Isso pode ser corroborado pelo fato de que, do período II em relação ao período I, houve quedas significativas dos principais mercados importadores brasileiros. A China teve um decréscimo de 72,5\%; a União Europeia, de 4,94\%; e o Irã, de 4\%.

\subsubsection{Período III em relação ao período II}

A decomposição das fontes de crescimento do óleo de soja, do período III em relação ao período II, indica que todos os efeitos, competitividade, crescimento do comércio mundial e destino, foram positivos.

O efeito competitividade contribuiu com $17,29 \%$ para explicar as exportações de óleo de soja. Contudo, houve uma forte queda nesse efeito em relação ao período anterior, que pode estar relacionada à baixa capacidade de esmagamento das unidades processadoras do Brasil, quando comparada à dos principais concorrentes no mercado internacional, ao aumento do consumo de óleo de soja e aos custos de transporte e logística elevados, principalmente para o óleo, que tem custos de transportes maiores que o grão e o farelo, dadas as suas especificidades.

Além disso, merecem destaque, de acordo com Gasques e Villa Verde (1998), a elevada carga tributária, com custos diretos sobre as empresas processadoras, o que colabora para reduzir a rentabilidade da operação, e o crescimento de produtos substitutivos como os óleos de palma, girassol e canola. 
Podem-se destacar, além das variáveis elencadas, outros fatores que colaboraram para o Brasil perder competividade nesse segmento: forte competitividade no mercado internacional, com o crescimento da produção da Argentina e do Leste Asiático, conforme a FAO (2009); o preço mais atrativo do grão e do farelo, conforme Coronel (2008), o que faz com que os exportadores brasileiros deem preferência para as exportações dessas commodities; e as barreiras tarifárias que mercados como a China e União Europeia impõem ao óleo de soja.

O efeito crescimento do comércio mundial continuou sendo positivo, mas aumentou significativamente, fato que pode estar relacionado ao crescimento de aproximadamente $65 \%$ das exportações mundiais do período III em relação ao período II.

O efeito destino das exportações foi positivo, embora em pequena proporção, mas bem superior ao valor do período anterior, devido ao crescimento das exportações brasileiras de óleo de soja para todos os seus principais mercados do período III relação ao período II, ou seja, China, Índia, Irã e União Europeia, indicando que, nesse período, o Brasil não concentrou tanto as suas exportações em mercados estagnados.

\section{CONCLUSÃO}

Neste trabalho, constatou-se que o Brasil tem uma importância significativa na produção de soja, bem como nas exportações de soja em grão, farelo e óleo. O país é o segundo maior produtor mundial de grão, óleo e farelo e apresenta condições geográficas que lhe permitem aumentar ainda mais a produção dessa oleaginosa. O Brasil, desde 1996, com a implantação da Lei Kandir, vem privilegiando as exportações de grão em detrimento de farelo e óleo, os quais têm maior valor agregado, e o país teria condições de aumentar mais sua participação nesse mercado.

Para continuar como importante exportador do complexo soja, o Brasil precisa superar vários entraves internos, como redução dos custos de transporte e logística, melhores condições de infraestrutura e maiores investimentos em pesquisa. Também precisa buscar alternativas junto à Organização Mundial do Comércio (OMC) para a redução das barreiras tarifárias e não tarifárias que os principais importadores impõem ao agronegócio da soja. 
O modelo Constant-Market-Share aplicado neste trabalho permitiu indicar quais os fatores que mais influenciaram as exportações de grão, farelo e óleo de soja; contudo, é pertinente ressaltar que não se pode afirmar de maneira discriminada quais os fatores que influenciaram o efeito competitividade, uma vez que este é residual no modelo.

As análises das fontes de crescimento das exportações brasileiras de grão, do farelo e do óleo de soja apresentaram certa similaridade, visto que, para todas essas commodities, do período II em relação ao período I, o efeito competitividade foi o que mais influenciou as exportações. Contudo, do período III em relação ao período II, esse efeito continuou sendo importante para as exportações de todos esses produtos, mas caiu significativamente, e, no segundo período, o efeito crescimento do comércio mundial foi o que mais contribuiu para a exportação dos referidos produtos.

A queda do efeito competitividade de um período para outro pode estar relacionada a fatores como a sobrevalorização cambial do período 2003/2004; o alto custo de transporte e infraestrutura inadequados, que se deterioraram mais nos últimos anos, aumentando o custo Brasil; a falta de melhores condições de armazenagem; os vários problemas de logística que o país apresenta; o comportamento protecionista de alguns países, que acaba gerando perdas de competitividade; e a produção doméstica de rações e carnes, que dependem da soja. O efeito crescimento do comércio mundial, que no segundo período foi o fator que mais contribuiu para as exportações tanto do grão quanto do farelo e óleo, foi fortemente influenciado pelo aumento do fluxo comercial mundial do complexo soja ocorrido entre 2002 e 2004, que afetou as exportações brasileiras.

Os resultados deste trabalho permitem traçar um panorama do complexo soja brasileiro, bem como indicar quais os principais obstáculos internos e externos que devem ser superados e também quais os fatores que mais colaboraram para as exportações do agronegócio da soja, e ainda para quais mercados estão direcionadas as exportações. Poderá contribuir, desta forma, com indicações de possibilidades relacionadas à implementação de políticas comerciais, no sentido de redirecionar os produtos do complexo soja para mercados que apresentem maior dinamismo em suas importações.

A partir deste trabalho, vários outros aspectos podem ser analisados, tais como estudos mais avançados sobre a identificação de fatores relacionados 
à competitividade do complexo soja, analisando em face das exportações brasileiras, dos Estados Unidos e da Argentina, que são os principais concorrentes do Brasil nesse mercado, bem como simular cenários, através de modelos de Equilíbrio Geral Computável, Equilíbrio Gravitacional e de Alocação Espacial, os quais apontem os ganhos que o país poderá ter na perspectiva de quedas das barreiras tarifarias e não tarifárias que os principais mercados importadores impõem.

\section{REFERÊNCIAS BIBLIOGRÁFICAS}

CASSUCE, F. C. C.; SANTOS, M. L. dos. Desvalorizações cambiais e captação de divisas: o caso brasileiro de soja em grão. Revista Organizações Rurais e Agroindústrias, Lavras, v. 7, n. 3, p. 298-311, 2005.

CONFEDERAÇÃO NACIONAL DA AGRICULTURA (CNA). Agência CNA. 2008. Disponível em: $<$ http://www.cna.org.br>. Acesso em: 14 jun. 2008.

CORONEL, D. A. Fontes de crescimento e orientação regional das exportações brasileiras do complexo soja. (Dissertação de Mestrado em Agronegócios) — Programa de Pós-Graduação em Agronegócios, Centro de Estudos e Pesquisas em Agronegócios, Universidade Federal do Rio Grande do Sul, Porto Alegre, 2008.

et al. Exportações do complexo brasileiro de soja vantagens comparativas reveladas e orientação regional. Revista de Política Agrícola, v. XVII, p. 20-32, out./dez., 2008.

et al. Poder de mercado das exportações de farelo de soja: uma análise via demanda residual. In: CONGRESSO BRASILEIRO DE ECONOMIA E SOCIOLOGIA RURAL, 47, 2009, Porto Alegre. Anais. Porto Alegre: Sober, 2009. 1 CD-ROM

FERNANDES, L. A. et al. Respeito a norma, protecionismo ou oportunismo: uma análise da tomada de decisão chinesa no caso da soja brasileira. Facef Pesquisa, São Paulo, v. 8, n. 3, p. 61-70, 2005.

FIGUEIREDO, A. M.; SANTOS, M. L. dos. Evolução das vantagens comparativas do Brasil no comércio mundial. Revista de Política Agrícola, São Paulo, v. 1, p. 9-16, jan./mar. 2005.

FIGUEIREDO, A. M.; SANTOS, M. L. dos; LÍRIO, V. S. Análise de market-share e fontes de variação das exportações brasileiras de soja. Revista de Economia e Agronegócio, Viçosa, v. 2, n. 3, p. 335-360, jul./set. 2004.

FOOD AND AGRICULTURE ORGANIZATION OF THE UNITED NATIONS (FAO). Disponível em: $<$ http://www.fao.org > . Acesso em: 1 maio, 2009.

FRAGA, G. J. et al. O pass-through das variações da taxa de câmbio para os preços de exportação de soja. Revista Análise, Porto Alegre, n. 49, p. 193-210, 2008.

GASQUES, J. G.; VILLA VERDE, C. M. Competitividade de grãos e de cadeias selecionadas do agribusiness. Texto para Discussão, Brasília: IPEA, n. 538. 1998. 
ILHA, A. DA S.; CORONEL, D. A. Vantagens comparativas reveladas e orientação regional da soja brasileira frente à União Europeia e ao Foro de Cooperação Econômica na Ásia e no Pacífico (1992-2004). Revista de Economia e Agronegócio, Viçosa, v. 4, n. 1, p. 43-62, jan./ mar. 2006.

LEAMER, E. E; STERN, R. M. Quantitative international economics. Chicago: Allyn and Bacon, 1970.

MINISTÉRIO DA AGRICULTURA, PECUÁRIA E ABASTECIMENTO (MAPA). Agronegócio. 2008. Disponível em: <http://www.agricultura.gov.br> Acesso em: 24 abr. 2008.

MINISTÉRIO DO DESENVOLIMENTO INDÚSTRIA E COMÉRCIO EXTERIOR (MIDIC). Secretaria de Comércio Exterior (Secex). 2008. Disponível em: <http://www.mdic.gov.br/sitio/ secex/secex/informativo.php>. Acesso em: 20 mar. 2008.

ORGANIZAÇÃO MUNDIAL DO COMÉRCIO (OMC). Base de datos estadísticos. 2007. Disponível em: <http:www.wto.org >. Acesso: 25 maio 2008.

RICHARDSON, J. D. Constant-Market-Shares analyis of export growth. Journal of International Economics, v. 1, p. 227-239, jul. 1971.

SAMPAIO, L. M. B.; SAMPAIO, Y.; COSTA; E. de F. Mudanças políticas recentes e competitividade no mercado internacional de soja. Revista de Economia e Sociologia Rural, Brasília, v. 44, n. 3, p. 383-411, jul./set. 2006.

SECRETARIA DE COMÉRCIO EXTERIOR (Secex). 2008. Disponível em: <http://www.mdic. gov.br/sitio/secex/secex/informativo.php>. Acesso em: 20 mar. 2008.

SIQUEIRA, T. V. de. O ciclo da soja: desempenho da cultura da soja entre 1961 e 2003. BNDS Setorial, Rio de Janeiro, n. 20, p. 127-222, set. 2004.

SOUZA, S. S. S. de et al. Mudanças cambiais e o efeito dos fatores de crescimento das receitas de exportações brasileiras de soja. Revista de Economia e Agronegócio, Viçosa, v. 5, n. 1, p. 1-24, jan./mar. 2007. 